\title{
A HYBRID DYNAMIC MADM MODEL FOR PROBLEM-IMPROVEMENT IN ECONOMICS AND BUSINESS
}

\author{
Kua-Hsin PENGa ${ }^{a}$ Gwo-Hshiung TZENG ${ }^{b}$ \\ anstitute of Leisure and Recreation Management, Kainan University, \\ No. 1, Kainan Road, Luchu, Taoyuan 338, Taiwan \\ ${ }^{\mathrm{b}}$ Graduate Institute of Urban Planning, College of Public Affairs, National Taipei University, \\ No. 151, University Road, San Shia 237, Taiwan \\ ' Institute of Management of Technology, National Chiao-Tung University, \\ No. 1001, Ta-Hsueh Road, Hsin-Chu 300, Taiwan
}

Received 13 August 2012; accepted 13 April 2013

\begin{abstract}
A typical multiple attribute decision making (MADM) model is a scientific analytical model for evaluating and improving a set of alternatives based on multiple criteria. However, this study identified some important new concepts and limitations/defects of traditional MADM for solving the real-world problems. First, the traditional MADM model assumes that criteria considered are independent and hierarchical in structure; however, the real-world problems often involve interdependent criteria, and thus interdependent models are required. Second, relatively good solutions from existing alternatives are replaced by the aspiration levels. Third, the trend has shifted from how to "rank" or "select" the most preferable alternatives, to how to "improve" their performances. Fourth, information fusion/aggregation, such as fuzzy integrals, basically, a non-additive/super-additive model, has been developed for performance aggregation. Therefore, to overcome the defects of the conventional MADM method and solve complex and dynamic real world problems, a Hybrid Dynamic Multiple Criteria Decision Making (HDMADM) method is needed. Finally, this study presented real cases to demonstrate the effectiveness of the HDMADM method for overcoming the defects of the conventional MADM method.
\end{abstract}

Keywords: MCDM (Multiple Criteria Decision Making), MADM (Multiple Attribute Decision Making), MODM (Multiple Objective Decision Making), DEMATEL (Decision Making Trial and Evaluation Laboratory), DANP (DEMATEL-based ANP), Fuzzy integral, INRM (Influential Network Relationship Map), VIKOR, aspiration level.

Reference to this paper should be made as follows: Peng, K.-H.; Tzeng, G.-H. 2013. A hybrid dynamic MADM model for problem-improvement in economics and business, Technological and Economic Development of Economy 19(4): 638-660.

JEL Classification: C00, C02, C18, C54, C61, D70, D78, O20.

Corresponding author Gwo-Hshiung Tzeng

E-mail: ghtzeng@mail.ntpu.edu.tw; ghtzeng@cc.nctu.edu.tw 


\section{Introduction}

Decision making (DM) regarding single criterion problems is highly intuitive, being a simple matter of choosing the alternative with the highest preference rating. However, when DM evaluates alternatives involving multiple criteria, numerous problems, including criteria weights, preferences or influence dependence, and conflicts among criteria, complicate the problems and require sophisticated solutions (Tzeng, Huang 2011). Bernoulli proposed the expected-utility principle in 1738 (Luce, Raiffa 1957). Additionally, von Neumann and Morgenstern (1944) presented an expected utility criterion that typically aggregates these elements in ranking possible actions to decide the optimal selection. In the early 1970s, multiple criteria decision making (MCDM) was introduced as a promising and important field of study, then, research on MCDM has been increasing extremely (Carlsson, Fullr 1996; Wallenius et al. 2008). Multiple criteria decision making (MCDM) is a scientific analytical method for evaluating a set of alternatives by considering multiple criteria to determine a priority ranking and improvement for alternative implementation (Tsaur et al. 1997; Wang, Lee 2009; Chang et al. 2012). MCDM methods generally aim to help decision-makers make better decisions by selecting the best from among multiple feasible alternatives under the presence of multiple choice criteria and diverse criteria priorities (Jankowski 1995; Mollaghasemi, Pet-Edwards 1997). Additionally, MCDM methods attempt to improve decision quality, through clearer, more reasonable and more efficient decision processes.

Hwang and Yoon (1981) classified MCDM problems into two main categories, namely multiple attribute decision making (MADM) and multiple objective decision making (MODM) (Fig. 1), based on the different purposes and data types. The former mainly involve the evaluation/improvement/selection facets/dimensions, which are usually associated with a limited number of predetermined alternatives and discrete preference ratings. The latter category exist particularly in the areas of design/planning, and generally involve attempting to optimize goals by considering the various interactions within the given constrains, so that both decision and objective spaces are changeable in new research concepts. However, this study proposed that the traditional MCDM ignores some important new concepts and limitations/defects for solving the real-world problems. First, conventional MADM assumes independent criteria with a hierarchical structure. However, relationships among criteria or dimensions are usually interdependent for real-world problems, and in some cases feedback effects exist. The criteria in practical MADM problems are generally interactive, and thus some interdependent models have been proposed (such as DANP (DEMATEL-based ANP), etc.). Second, conventional MADM only obtains relatively good solutions from existing alternatives, but also avoids "choosing the best among inferior choices/options/alternatives", i.e. avoids "Pick the best apple from a barrel of rotten apples", it should be replaced by the aspiration levels. Third, conventional MADM merely allows the selection and ranking of alternatives or strategies, but these alternative methods shift the focus from how to conduct "ranking" or "selection" of the most preferable alternatives to how to "improve" them. Fourth, information fusion/aggregation, such as fuzzy integral, a non-additive/super-additive model, has been developed for performance aggregation. Therefore, a Hybrid Dynamic Multiple Attribute Decision Making (HDMADM) method is needed to overcome the defects of the 


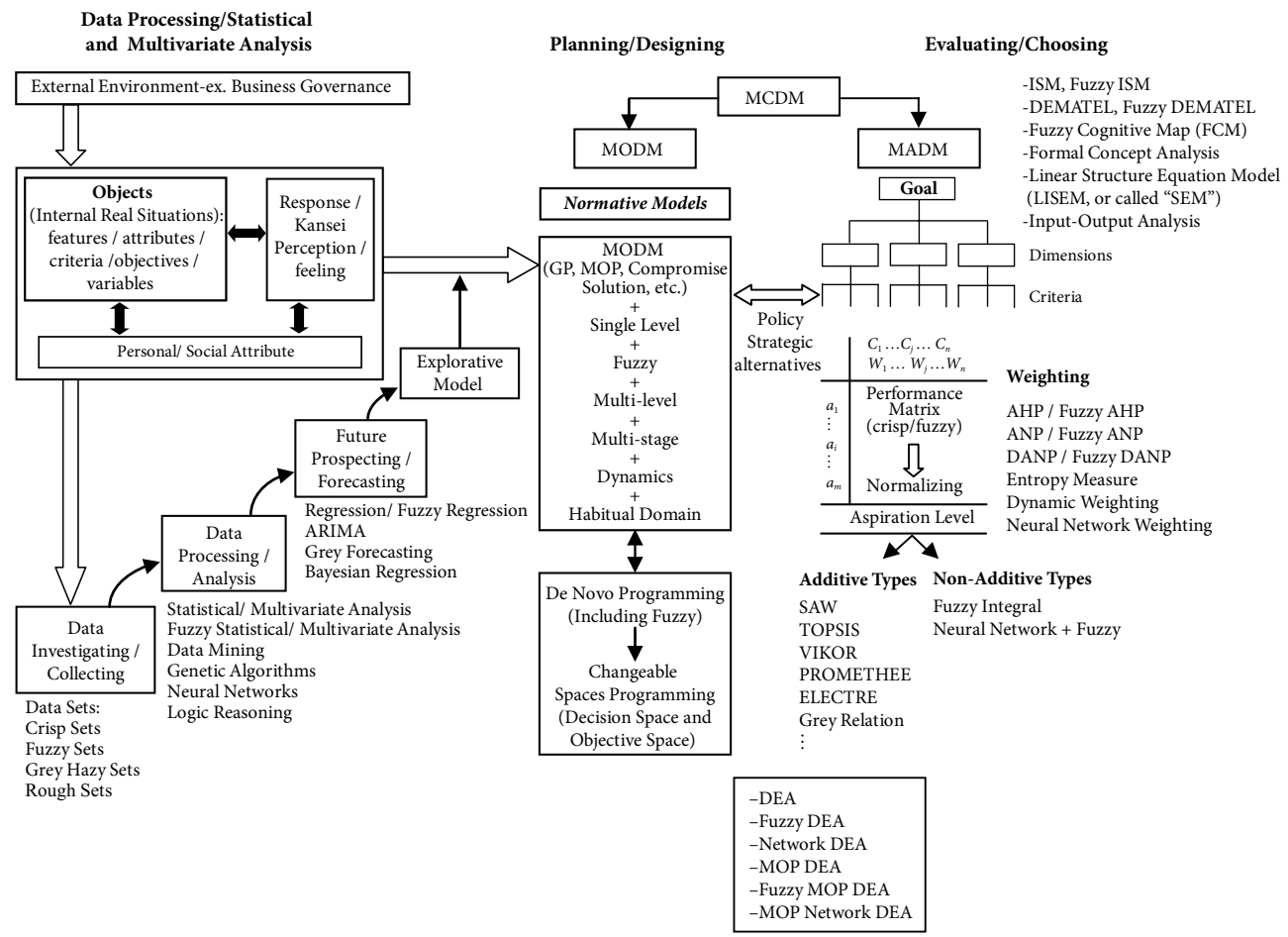

Fig. 1. Basic concepts on overview of social science research with MCDM (Liou, Tzeng 2012)

conventional MADM method and solve the complications of dynamic problems in the real world (Campanella, Ribeiro 2011). This study presented two categories of HDMADM. The first category used the basic concept of ANP (Saaty 1996) with DEMATEL (call DANP, DEMATEL-based ANP) to yield influential weights of dimensions/criteria, and combined influential weights with the additive types of VIKOR. The second category also used DANP to yield influential weights of dimensions/criteria, but combined the influential weights of the DANP with non-additive/super-additive types of fuzzy integral to assess and improve complex practical problems. Finally, this study presented two empirical cases to demonstrate the ability of the HDMADM method to overcome the defects of the conventional MADM method. The remainder of this paper is organized as follows. Section 1 reviews the MCDM method. Section 2 then introduce the HDMADM method. Subsequently, Section 3 presents some empirical cases to demonstrate the effectiveness of the HDMADM method. Finally, the last section presents conclusions.

\section{MCDM method}

For studies wishing to know how to develop improvement strategies to achieve the goal or aspiration level, for example pursuing higher performance, competitiveness and satisfactory service, an important question is which research methods are most suitable and practical for solving real world problems. Based on the above thinking, the first part of the study attempts to figure 
out how many attributes or criteria should consider. On the other hand, the study must collect adequate data that reflect the behaviors of attributes or criteria. Additionally, the study should build a set of possible alternatives or strategies to guarantee that the goal or aspiration level is achieved using MCDM methods. Then, the next step is to select appropriate MCDM methods that help decision-makers to evaluate, improve and choose possible alternatives or strategies.

Multiple criteria decision making (MCDM) is a scientific analytical method for evaluating a set of alternatives based on multiple criteria (Campanella, Ribeiro 2011; Tsaur et al. 1997; Wang, Lee 2009; Loban 1997). MCDM techniques have been used in recent years to solve a wide variety of problems (Chen, Liao 2004; Hung, Chiang 2008; Ou Yang et al. 2008), such as supplier selection (Deng, Chan 2011); performance evaluation of higher education (Wu et al. 2012); improving airline's service quality (Kuo 2011); evaluating website quality (Chou, Cheng 2012); product design and selection (Liu 2011); evaluating hot spring hotels service quality (Tseng 2011); prioritizing sustainable electricity production technologies (Streimikiene et al. 2012), etc. Additionally, most MCDM problems in the real world thus occur in hybrid situations, which include goals, aspects (or dimensions), attributes (or criteria), and possible alternatives (or strategies). Furthermore, most real-world decision problems are dynamic, however, the traditional MCDM model is unable to capture this dynamicity (Campanella, Ribeiro 2011) and hybrid situation, thus, should develop a suitable HDMADM method to solve complication dynamic problems in the real world.

\section{Methodology for solving the real world problems}

This section is divided into five parts: the first part describes the concept of HDMADM method, the second part presents DEMATEL method, the third part presents DANP, the fourth part presents VIKOR method, and the last part describes fuzzy integral for focusing on how to aggregate the performance in non-additive/super-additive situations to suit the real world problems.

\subsection{Hybrid Dynamic Multiple Attribute Decision Making (HDMADM)}

This study proposed the DEMATEL technique and combines a DANP with additive types of VIKOR and non-additive types of fuzzy integral to address the problems of conventional MADM method. The DEMATEL technique is used to build an influential network relations map (INRM), then for obtaining the influential weights of each criterion, DANP use the basic concept of ANP (Saaty 1996) and taking the transpose of normalized total-influence matrix $\boldsymbol{T}_{c}$ (denoting $\left(\boldsymbol{T}_{c}^{\alpha}\right)^{\prime}$ ) by dimensions to get the un-weighted super-matrix $\boldsymbol{W}_{c}\left(\right.$ i.e. $\left.\boldsymbol{W}_{c}=\left(\boldsymbol{T}_{c}^{\alpha}\right)^{\prime}\right)$ and taking the normalized total-influence matrix $\boldsymbol{T}_{D}$ (obtaining $\boldsymbol{T}_{D}^{\alpha}$ ) multiplying the un-weighted super-matrix $\boldsymbol{W}_{c}$ to obtain the weighted super-matrix $\boldsymbol{W}_{c}^{\alpha}\left(\right.$ i.e. $\left.\boldsymbol{W}_{c}^{\alpha}=\boldsymbol{T}_{D}^{\alpha} \boldsymbol{W}_{c}\right)$. According to the weighted super-matrix $W_{c}^{\alpha}$, it multiplies by itself multiple times to obtain limit super-matrix $\lim _{\phi \rightarrow \infty}\left(\boldsymbol{W}_{c}^{\alpha}\right)^{\phi}$ (Appendix B). Then, the VIKOR method or Fuzzy Integral with influential weights (DANP) is used to integrate the performance gaps. Finally, it is possible to determine how to improve performance and reduce the gaps to achieve the aspiration level based on INRM. The processes of HDMADM are illustrated as Fig. 2. 


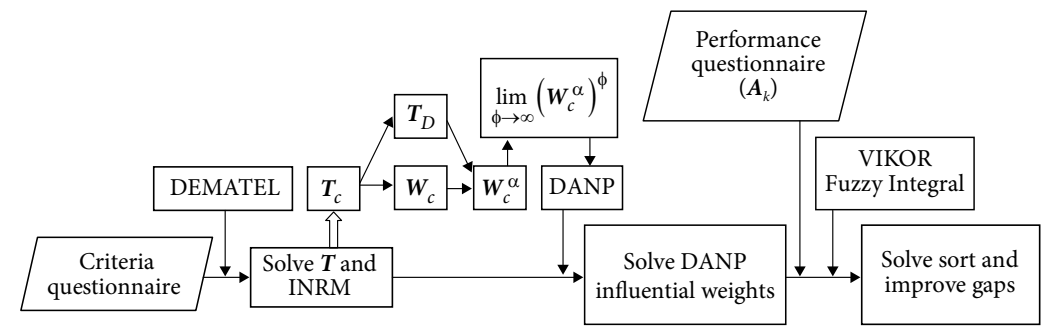

Fig. 2. Model procedures of Hybrid Dynamic Multiple Attribute Decision Making (HDMADM) (Chiu et al. 2013)

\subsection{DEMATEL method}

DEMATEL is an analytical technique for building a structural model. DEMATEL is mainly used to clarify and solve complex problems. DEMATEL uses matrix and related mathematical theories (Boolean operation) to calculate the cause and effect relationships involved in each element. This technique is widely used to solve various complex problems, and particularly to understand complex problem structures and provide practical problem-solving methods. The DEMATEL technique involves five steps (see Appendix A). The first step is to confirm that the system has $n$ elements and develop the evaluation scale, using a pair-wise of dimensions to perform the comparison, and also using the measuring scale $0,1,2,3,4$, where (0) represents no influence whatsoever, (1) represents low influence, (2) represents medium influence, (3) represents high influence, and (4) represents extremely high influence. The second step calculates the initial matrix to directly obtain the influential matrix (Lin, Tzeng 2009; Chen et al. 2010). The third step normalizes the matrix such that at least one column or row, but not all, sums to one. The fourth step then obtains the total influence matrix. Finally, the fifth step builds the influential network relation map (INRM).

\subsection{Finding the influential weights using DANP}

This study not only uses the DEMATEL technique to build the interactive relationship among the various dimensions/criteria, but also seeks the most accurate influential weights. This study found that ANP can serve this purpose. This study used the basic concept of ANP (Saaty 1996), which eliminates the limitations of Analytic Hierarchy Process (AHP) and is applied to solve nonlinear and complex network relations (Saaty 1996). DANP is intended to solve interdependence and feedback problems of criteria in influential weights. This study thus applies the characteristics of influential weights based on basic concept of ANP and combines them with DEMATEL (call DANP, DEMATEL-based ANP) to solve these kinds of problems (see Appendix B). This approach yields more practical results in real world problem.

\subsection{VIKOR Method}

The VIKOR (VlseKriterijumska Optimizacija I Kompromisno Resenje) method (see Appendix C) was developed for multicriteria optimization of complex systems. It introduces the multicriteria ranking index based on the particular measure of "closeness" to the "ideal" solution (Opricovic 1998). VIKOR uses the class distance function (Yu 1973) based on the concept of 
the positive-ideal (or in this study adopt the Aspiration level) solution and negative-ideal (or in this study adopt the Worst level) solution and orders the results. For normalized class distance function it is better to be near the positive-ideal points (the aspiration level) and far from the negative-ideal point (the worst value) for normalized class distance function (Lee et al. 2009; Ho et al.2011). Opricovic and Tzeng (2004) proposed the compromise ranking method (VIKOR) as a suitable technique for implementation within MCDM (Tzeng et al. 2002a, b, 2005; Opricovic, Tzeng 2002, 2003, 2007). VIKOR comprises the following steps: The first step is to check the best and worst values of the assessment criteria. The second step is to calculate the mean group utility based on the sum of all individual-criterion regrets (i.e. average overall performance gaps, and those for each dimension, and for each criterion; and strategies for reducing these gaps), and calculate the maximal regret for an individual-criterion for improvement priority, both overall and for each dimension. The third step is to obtain the comprehensive/integrating indicators and sort the results provided to the decision-maker to implement improvement strategies and reduce competitiveness gaps in both overall performance and individual dimensions of performance.

\subsection{The $\lambda$ fuzzy measure and fuzzy integral}

In order to overcome non-additive problem, Sugeno (1974) introduced the concept of fuzzy measure and fuzzy integral (see Appendix D). This study presents that used DANP to yield influential weights of dimensions/criteria, then combined the influential weights of the DANP with non-additive types of fuzzy integral to integrate the performance gaps and improve complex practical problems.

\section{An empirical case}

This section comprises two parts: the first part describes an empirical case involving Taiwan to explore strategies for improving tourism destination competitiveness (TDC) based on a HDMADM model using DEMATEL, DANP and VIKOR; the second part presents an empirical case involving a Taiwanese company for supplier evaluation and improvement based on a fuzzy integral-based hybrid MADM model that addresses the dependence/relationships among the various criteria and the non-additive gap-weighted analysis.

\subsection{Tourism destination competitiveness (TDC) of Taiwan}

The following presents an empirical case involving Taiwan to explore strategies for improving tourism destination competitiveness (TDC) using a HDMADM model. This study identifies three dimensions of expert cognition and opinion, and also identifies the relationship between the degrees of the impact, which is compared with other dimensions, as listed in Table 1. According to the total influential prominence $\left(r_{i}+d_{i}\right)$, "Regulatory framework $\left(D_{1}\right)$ ) is the highest total influential prominence among other factors that means the most important influencing factors; additionally, "Human cultural and natural resources $\left(D_{3}\right)$ " is the factors with the weakest total influential prominence among other factors. According to the influential relation $\left(r_{i}-d_{i}\right)$, "Regulatory framework $\left(D_{1}\right)$ " represents the highest degree of impact relationship and directly affects other factors. Otherwise, "Business environment and infrastructure $\left(D_{2}\right)$ ” is more vulnerable to influence than other dimensions. 
Table 1. Total influential matrix of $\boldsymbol{T}$ and the sum of the effects on the dimensions

\begin{tabular}{|c|c|c|c|c|c|c|c|c|}
\hline \multicolumn{2}{|c|}{ Dimensions } & \multirow{2}{*}{$\begin{array}{r}D_{1} \\
0.305\end{array}$} & \multirow{2}{*}{$\begin{array}{r}D_{2} \\
0.825\end{array}$} & \multirow{2}{*}{$\begin{array}{r}D_{3} \\
0.782\end{array}$} & & \multirow{2}{*}{$\begin{array}{l}d_{i} \\
0.916\end{array}$} & \multirow{2}{*}{$\begin{array}{l}\frac{r_{i}+d_{i}}{2.828} \\
\end{array}$} & \multirow{2}{*}{$\begin{array}{r}r_{i}-d_{i} \\
0.996\end{array}$} \\
\hline$D_{1}$ & Regulatory framework & & & & & & & \\
\hline$D_{2}$ & $\begin{array}{l}\text { Business environment and } \\
\text { infrastructure }\end{array}$ & 0.321 & 0.237 & 0.332 & 0.891 & 1.497 & 2.388 & -0.606 \\
\hline$D_{3}$ & $\begin{array}{l}\text { Human cultural and } \\
\text { natural resources }\end{array}$ & 0.290 & 0.435 & 0.208 & 0.932 & 1.322 & 2.254 & -0.389 \\
\hline
\end{tabular}

Note : $\frac{1}{n^{2}} \sum_{i=1}^{n} \sum_{j=1}^{n} \frac{\left|t_{i j}^{p}-t_{i j}^{p-1}\right|}{t_{i j}^{p}} \times 100 \%=3.11 \%<5 \%$, i.e. significant confidence is $96.89 \%$, where $p=10$ denotes the number of experts and $t_{i j}^{p}$ is the average influence of $i$ criterion on $j$; and $n$ denotes number of dimensions, here $n=3$ and $n \times n$ matrix.

Table 2 lists the relationship between the direct or indirect impacts and compares them with other criteria. "Prioritization of Travel and Tourism $\left(C_{5}\right)$ " is the most important criterion among those considered; additionally, "Safety and security $\left(C_{3}\right)$ " is the criterion with the smallest impact on other criteria. Furthermore, Table 2 shows that "Policy rules and regulations $\left(C_{1}\right)$ " has the strongest relationship among all the criteria. Otherwise, "Tourism infrastructure $\left(C_{8}\right)$ " is the most vulnerable criteria to outside influences.

Table 2. The sum of influences, weights and rankings of each criterion

\begin{tabular}{|c|c|c|c|c|c|c|}
\hline Dimensions/Criteria & $r_{i}$ & $d_{i}$ & $r_{i}+d_{i}$ & $r_{i}-d_{i}$ & $\begin{array}{c}\text { Degree of } \\
\text { importance } \\
\text { (Global weight) }\end{array}$ & Ranking \\
\hline$D_{1}$ Regulatory framework & & & & & 0.2866 & 3 \\
\hline$C_{1}$ Policy rules and regulations & 1.750 & 0.882 & 2.633 & 0.868 & 0.0544 & 3 \\
\hline$C_{2}$ Environmental sustainability & 0.865 & 0.933 & 1.798 & -0.068 & 0.0546 & 2 \\
\hline$C_{3}$ Safety and security & 0.716 & 0.846 & 1.562 & -0.131 & 0.0500 & 5 \\
\hline $\mathrm{C}_{4}$ Health and hygiene & 0.764 & 0.886 & 1.651 & -0.122 & 0.0537 & 4 \\
\hline $\begin{array}{ll}C_{5} & \text { Prioritization of Travel and } \\
\text { Tourism }\end{array}$ & 1.857 & 1.192 & 3.048 & 0.665 & 0.0739 & 1 \\
\hline $\begin{array}{ll}D_{2} & \text { Business environment } \\
\text { and infrastructure }\end{array}$ & & & & & 0.3803 & 1 \\
\hline$C_{6}$ Air transport infrastructure & 0.726 & 0.935 & 1.661 & -0.209 & 0.0744 & 3 \\
\hline$C_{7}$ Ground transport & 0.735 & 0.936 & 1.670 & -0.201 & 0.0739 & 4 \\
\hline$C_{8}$ Tourism infrastructure & 0.754 & 1.020 & 1.774 & -0.266 & 0.0809 & 1 \\
\hline$C_{9}$ ICT infrastructure & 0.734 & 0.884 & 1.618 & -0.150 & 0.0717 & 5 \\
\hline$C_{10}$ Price competitiveness & 0.690 & 1.014 & 1.704 & -0.325 & 0.0794 & 2 \\
\hline $\begin{array}{ll}D_{3} & \begin{array}{l}\text { Human cultural } \\
\text { and natural resources }\end{array}\end{array}$ & & & & & 0.3332 & 2 \\
\hline$C_{11}$ Human resources & 1.103 & 0.778 & 1.881 & 0.325 & 0.0769 & 4 \\
\hline$C_{12}$ Affinity for travel \& tourism & 0.729 & 0.930 & 1.659 & -0.202 & 0.0837 & 3 \\
\hline $\begin{array}{ll}C_{13} & \text { Natural resources } \\
\end{array}$ & 0.884 & 0.896 & 1.780 & -0.013 & 0.0841 & 2 \\
\hline$C_{14}$ Culture resources & 0.803 & 0.977 & 1.781 & -0.174 & 0.0885 & 1 \\
\hline
\end{tabular}


This study builds the assessment model using DEMATEL, which is combined with the DANP (DEMATEL-based ANP) model to obtain the influential weights of each criterion, as listed in Table 2. Furthermore, the influential weights combine with the VIKOR in weightings to assess the priority of problem-solving improvement based on the competitiveness gaps identified by VIKOR and the influential relation map.

A real case involving Taiwan is used to assess the total competitiveness using the VIKOR method, as listed in Table 3. The scores of each criterion and the total average gap $\left(S_{k}\right)$ of Taiwan are obtained, using the relative influential weights from DANP to multiply the gap $\left(r_{k j}\right)$. Consequently, this study obtains the total competitiveness gap of Taiwan.

Additionally, to improve the human cultural and natural resources $\left(D_{3}\right)$ dimension, this study finds that the criterion of "Natural resources $\left(C_{13}\right)$ " is the maximal performance gap. Furthermore, the criterion of "Human resources $\left(C_{11}\right)$ " is the most important and influential criterion, and thus can be considered the critical criterion for improving natural resources. Thus, "Human resources $\left(C_{11}\right)$ " can be considered the critical criterion for improving the regulatory framework. Additionally, the comprehensive indicator $\left(R_{k}\right)$ can be obtained,

Table 3. The performance evaluation of the case study by VIKOR

\begin{tabular}{lcccc}
\hline \multirow{2}{*}{ Dimensions / Criteria } & $\begin{array}{c}\text { Local } \\
\text { weights }\end{array}$ & $\begin{array}{c}\text { Global } \\
\text { weights } \\
\text { (by DANP) }\end{array}$ & Case study of Taiwan \\
\cline { 5 - 6 }$D_{1}$ Regulatory framework & $\mathbf{0 . 2 8 6 6 ( 3 )}$ & & $\mathbf{4 . 4 0}$ & Gap $\left(r_{k j}\right)$ \\
\hline$C_{1}$ Policy rules and regulations & 0.1898 & $0.0544(3)$ & 4.80 & 0.367 \\
\hline$C_{2}$ Environmental sustainability & 0.1905 & $0.0546(2)$ & 4.20 & 0.467 \\
\hline$C_{3}$ Safety and security & 0.1745 & $0.0500(5)$ & 5.50 & 0.250 \\
\hline$C_{4}$ Health and hygiene & 0.1874 & $0.0537(4)$ & 3.30 & 0.617 \\
\hline$C_{5}$ Prioritization of travel and tourism & 0.2579 & $0.0739(1)$ & 4.20 & 0.467 \\
\hline$D_{2}$ Business environment & & & 4.90 & $\mathbf{0 . 3 5 7}$ \\
\hline$C_{6}$ Air transport infrastructure & $\mathbf{0 . 3 8 0 3 ( 1 )}$ & & 3.80 & 0.533 \\
\hline$C_{7}$ Ground transport & 0.1956 & $0.0744(3)$ & 5.70 & 0.217 \\
\hline$C_{8}$ Tourism infrastructure & 0.1943 & $0.0739(4)$ & 4.40 & 0.433 \\
\hline$C_{9}$ ICT infrastructure & 0.2127 & $0.0809(1)$ & 5.30 & 0.283 \\
\hline$C_{10}$ Price competitiveness & 0.1885 & $0.0717(5)$ & 5.10 & 0.317 \\
\hline$D_{3}$ Human cultural and natural resources & $\mathbf{0 . 3 3 3 2 ( 2 )}$ & & $\mathbf{3 . 9 0}$ & $\mathbf{0 . 5 1 7}$ \\
\hline$C_{11}$ Human resources & 0.2308 & $0.0769(4)$ & 5.70 & 0.217 \\
\hline$C_{12}$ Affinity for travel and tourism & 0.2512 & $0.0837(3)$ & 4.60 & 0.400 \\
\hline$C_{13}$ Natural resources & 0.2524 & $0.0841(2)$ & 2.40 & 0.767 \\
\hline$C_{14}$ Culture resources & 0.2656 & $0.0885(1)$ & 2.90 & 0.683 \\
\hline Total performances & & & $\mathbf{4 . 4 0}$ & - \\
\hline Total gap $\left(S_{k}\right.$ ) & & & $\mathbf{0 . 4 3 7}$ \\
\hline
\end{tabular}


which value of $v$ can determine by the expert that is defined as $v=0.5$ in this paper. This study identifies the comprehensive indicator $\left(R_{k}\right)$ as 0.602 , indicating that the Taiwanese government must improve the gap of TDC. Furthermore, the government can identify the problem-solving strategy according to the DEMATEL technique combined with DANP and VIKOR (called the hybrid MCDM model).

The DEMATEL technique (Fig. 3) can obtain valuable cues for making accurate decisions. This system structure model reveals that Taiwan suffers a significant gap in the "Human cultural and natural resources $\left(D_{3}\right)$ " dimensions, making it necessary focus on the

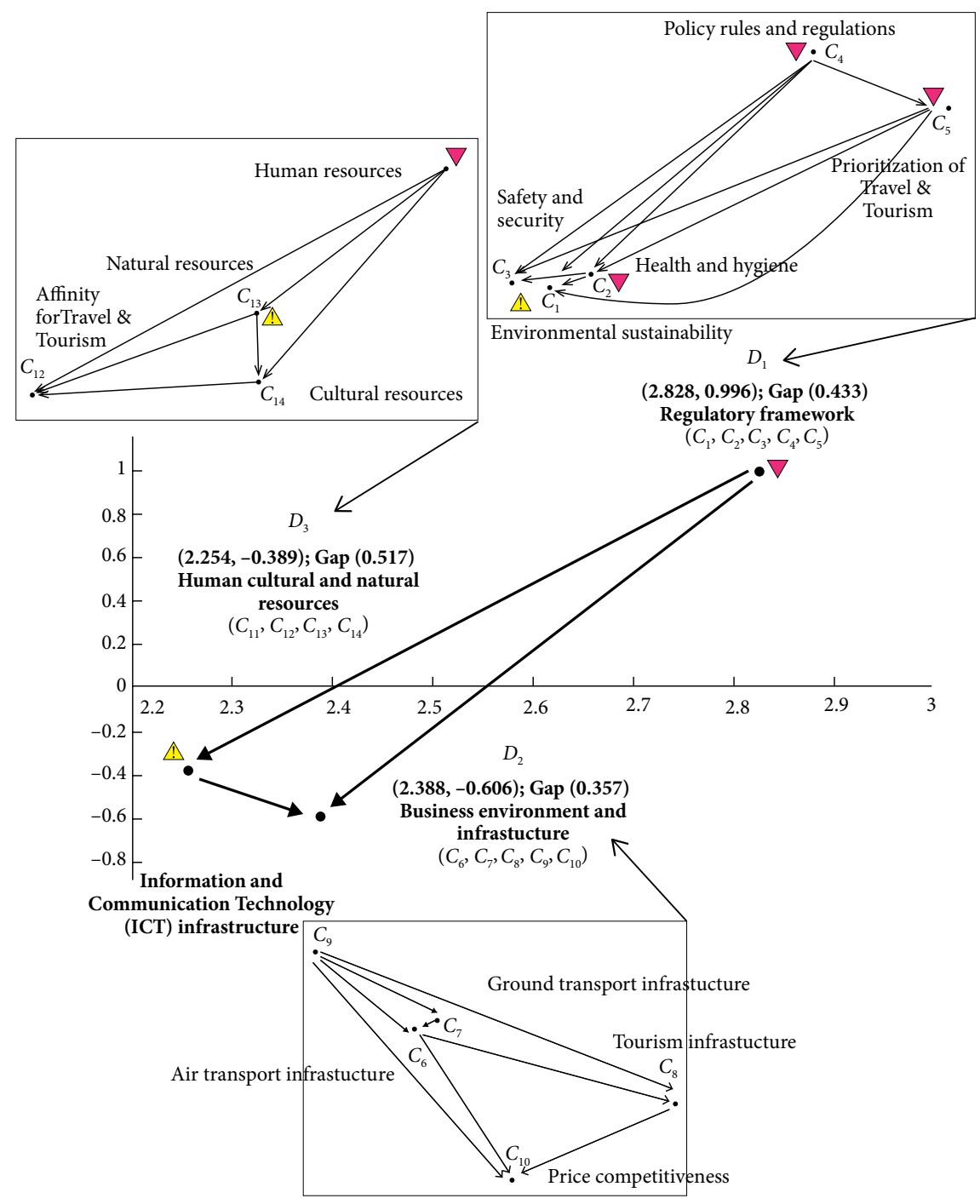

Fig. 3. The influential network relations map of each dimension and criteria 
"Regulatory framework $\left(D_{1}\right)$ " dimensions for improving the TDC of Taiwan. Furthermore, for improving the regulatory framework $\left(D_{1}\right)$ dimension, this study finds that the criterion of "Health and hygiene $\left(C_{4}\right)$ " prioritizes reducing the maximal competitiveness gap. Fig. 3 reveals that the criteria of "Policy rules and regulations $\left(C_{1}\right)$ ", "Prioritization of Travel \& Tourism $\left(C_{5}\right)$ " and Environmental sustainability $\left(C_{2}\right)$ are the most important and influential criteria because they are most closely related to other criteria in the $\left(D_{1}\right)$ dimension. Additionally, for improving the human cultural and natural resources $\left(D_{3}\right)$ dimension, this study finds that the criterion of "Natural resources $\left(C_{13}\right)$ " is the maximal performance gap. Furthermore, the criteria of "Human resources $\left(C_{11}\right)$ " is the most important and influential criteria, and thus can be considered the critical criteria for improving natural resources. Thus, the criteria of "Human resources $\left(C_{11}\right)$ " can be considered the critical criterion for improving the regulatory framework.

Consequently, Fig. 3 shows valuable cues for making accurate decisions. The influential network relations map provides an initial tool for demonstrating that the degrees of influence differ among dimensions and criteria. This study utilizes the most important and influential criteria as critical factors to improve the maximal gap of competitiveness.

\subsection{Supplier evaluation and improvement involving a Taiwanese company}

The supplier selection four dimensions and 11 criteria are developed based on literature review and discussions with the managers of the case company. Following the DEMATEL method, the influential network-relationship can be visualized by drawing an influential network-relationship map (INRM) of the four dimensions and their subsystems, as shown in Fig. 4 (the contents summarized from Tzengs' research group (Liou et al. 2012)).

This real case study used the DANP (DEMATEL-based ANP) model to obtain the influential weights of each criterion, as listed in Table 4.

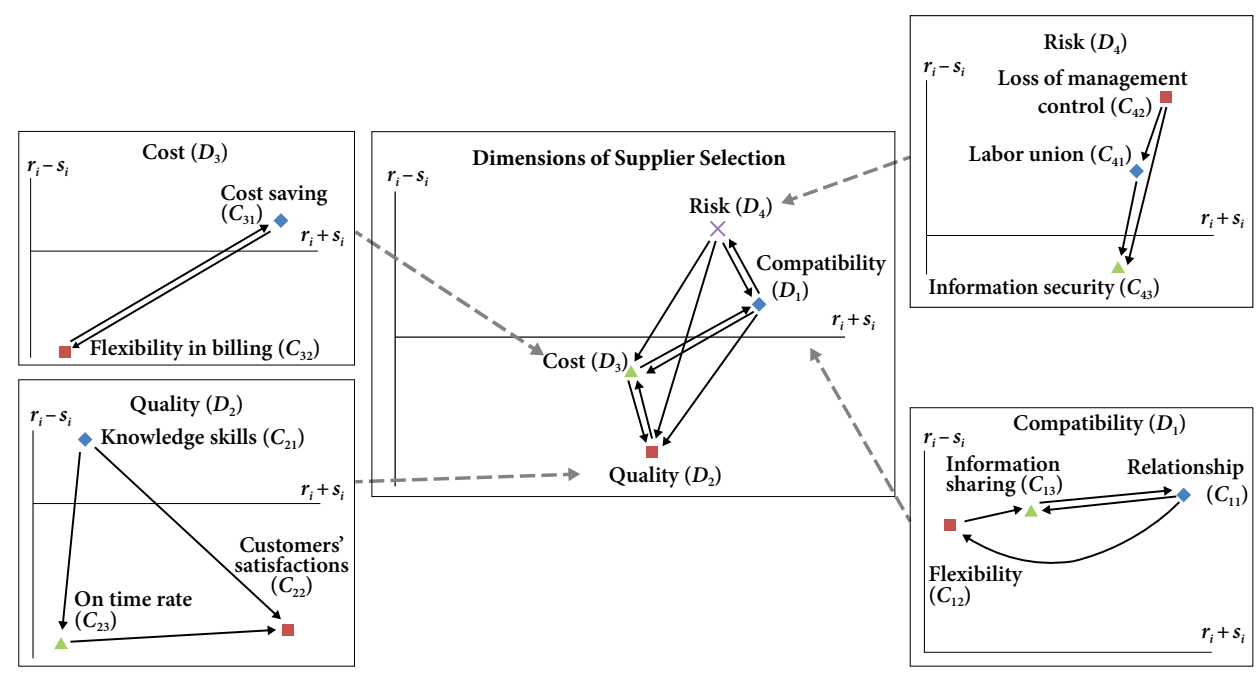

Fig. 4. Influential network-relationship map within systems Source: Liou et al. (2012). 
Table 4. Influential weights of system factors

\begin{tabular}{|c|c|c|c|c|c|c|}
\hline Dimensions & $\begin{array}{c}\text { Local } \\
\text { Weights }\end{array}$ & Rankings & Criteria & $\begin{array}{c}\text { Local } \\
\text { Weights }\end{array}$ & Rankings & $\begin{array}{l}\text { Global } \\
\text { Weights }\end{array}$ \\
\hline \multirow[t]{3}{*}{$D_{1}$ Compatibility } & \multirow[t]{3}{*}{0.306} & \multirow[t]{3}{*}{1} & $C_{11}$ Relationship & 0.367 & 1 & 0.112 \\
\hline & & & $C_{12}$ Flexibility & 0.310 & 3 & 0.095 \\
\hline & & & $C_{13}$ Information sharing & 0.324 & 2 & 0.099 \\
\hline \multirow[t]{3}{*}{$D_{2}$ Quality } & \multirow[t]{3}{*}{0.231} & \multirow[t]{3}{*}{3} & $C_{21}$ Knowledge skill & 0.281 & 3 & 0.065 \\
\hline & & & $C_{22}$ Customers' satisfactions & 0.379 & 1 & 0.088 \\
\hline & & & $C_{23}$ On time rate & 0.340 & 2 & 0.079 \\
\hline \multirow[t]{2}{*}{$D_{3}$ Cost } & \multirow[t]{2}{*}{0.204} & \multirow[t]{2}{*}{4} & $C_{31}$ Cost saving & 0.506 & 1 & 0.103 \\
\hline & & & $C_{32}$ Flexibility in billing & 0.494 & 2 & 0.101 \\
\hline \multirow[t]{3}{*}{$D_{4}$ Risk } & \multirow[t]{3}{*}{0.259} & \multirow[t]{3}{*}{2} & $C_{41}$ Labor union & 0.327 & 2 & 0.085 \\
\hline & & & $C_{42}$ Loss of management control & 0.351 & 1 & 0.091 \\
\hline & & & $C_{43}$ Information security & 0.322 & 3 & 0.083 \\
\hline
\end{tabular}

Source: Liou et al. (2012).

This real case study utilizes fuzzy integrals to aggregate the weighted gaps. Because the criteria within the same dimension have interdependent relationships, their weighted gaps should be integrated rather than being treated as individual values. Similarly, the integrated weighted gaps of the four dimensions should be further considered with their final synthesized values. Through a questionnaire survey conducted by managers of the case study company, the fuzzy integral l values, which range from -1 to positive infinity $\infty$ (i.e. $-1 \leq \lambda<\infty$ ), that represent the properties of substitution or multiplication between criteria are obtained. Substitutive effects exist among attributes of risk, and a multiplicative effect exists among compatibility, quality, and cost. Table 5 lists the 1 values and the fuzzy measures $g(\cdot)$.The integrated weighted gaps of each potential supplier are then calculated as shown in Table 6 (the contents summarized from Tzengs' research group (Liou et al. 2012)).

Table 5. Fuzzy measure $g(\lambda)$ of each parameter and parameter combination

\begin{tabular}{llll}
\hline Fuzzy Measure $g(\cdot)$ & & \\
\hline Supplier Selection (evaluating systems) $\lambda=-0.597, q=1.358$ \\
\hline$g_{\lambda}\left(\left\{D_{1}\right\}\right)=0.415$ & $g_{\lambda}\left(\left\{D_{1}, D_{2}\right\}\right)=0.651$ & $g_{\lambda}\left(\left\{D_{1}, D_{2}, D_{3}\right\}\right)=0.821$ & $g_{\lambda}\left(\left\{D_{1}, D_{2}, D_{3}, D_{4}\right\}\right)=1$ \\
$g_{\lambda}\left(\left\{D_{2}\right\}\right)=0.314$ & $g_{\lambda}\left(\left\{D_{1}, D_{3}\right\}\right)=0.624$ & $g_{\lambda}\left(\left\{D_{1}, D_{2}, D_{4}\right\}\right)=0.866$ & \\
$g_{\lambda}\left(\left\{D_{3}\right\}\right)=0.277$ & $g_{\lambda}\left(\left\{D_{1}, D_{4}\right\}\right)=0.680$ & $g_{\lambda}\left(\left\{D_{1}, D_{3}, D_{4}\right\}\right)=0.844$ & \\
$g_{\lambda}\left(\left\{D_{4}\right\}\right)=0.352$ & $g_{\lambda}\left(\left\{D_{2}, D_{3}\right\}\right)=0.539$ & $g_{\lambda}\left(\left\{D_{2}, D_{3}, D_{4}\right\}\right)=0.778$ & \\
& $g_{\lambda}\left(\left\{D_{2}, D_{4}\right\}\right)=0.600$ & \\
& $g_{\lambda}\left(\left\{D_{3}, D_{4}\right\}\right)=0.571$ & \\
\hline Compatibility $\left(D_{1}\right) \lambda=0.358, q=0.900$ & \\
\hline$g_{\lambda}\left(\left\{C_{11}\right\}\right)=0.330$ & $g_{\lambda}\left(\left\{C_{11}, C_{12}\right\}\right)=0.642$ & $g_{\lambda}\left(\left\{C_{11}, C_{12}, C_{13}\right\}\right)=1$ \\
$g_{\lambda}\left(\left\{C_{12}\right\}\right)=0.279$ & $g_{\lambda}\left(\left\{C_{11}, C_{13}\right\}\right)=0.656$ & \\
$g_{\lambda}\left(\left\{C_{13}\right\}\right)=0.291$ & $g_{\lambda}\left(\left\{C_{12}, C_{13}\right\}\right)=0.599$ & \\
\hline
\end{tabular}




\begin{tabular}{|c|c|}
\hline Fuzzy Measure $g(\cdot)$ & \\
\hline Quality $\left(D_{2}\right) \lambda=3.902, q=0.539$ & \\
\hline $\begin{array}{ll}g_{\lambda}\left(\left\{C_{21}\right\}\right)=0.151 & g_{\lambda}\left(\left\{C_{21}, C_{22}\right\}\right)=0.476 \\
g_{\lambda}\left(\left\{C_{22}\right\}\right)=0.204 & g_{\lambda}\left(\left\{C_{21}, C_{23}\right\}\right)=0.443 \\
g_{\lambda}\left(\left\{C_{23}\right\}\right)=0.183 & g_{\lambda}\left(\left\{C_{22}, C_{23}\right\}\right)=0.533\end{array}$ & $g_{\lambda}\left(\left\{C_{21}, C_{22}, C_{23}\right\}\right)=1$ \\
\hline $\operatorname{Cost}\left(D_{3}\right) \lambda=1.268, q=0.798$ & \\
\hline $\begin{array}{l}g_{\lambda}\left(\left\{C_{31}\right\}\right)=0.403 \\
g_{\lambda}\left(\left\{C_{33}\right\}\right)=0.395\end{array}$ & \\
\hline Risk $\left(D_{4}\right) \lambda=-0.073, q=1.025$ & \\
\hline $\begin{array}{ll}g_{\lambda}\left(\left\{C_{41}\right\}\right)=0.336 & g_{\lambda}\left(\left\{C_{41}, C_{42}\right\}\right)=0.687 \\
g_{\lambda}\left(\left\{C_{42}\right\}\right)=0.360 & g_{\lambda}\left(\left\{C_{41}, C_{43}\right\}\right)=0.657 \\
g_{\lambda}\left(\left\{C_{43}\right\}\right)=0.330 & g_{\lambda}\left(\left\{C_{42}, C_{43}\right\}\right)=0.681\end{array}$ & $g_{\lambda}\left(\left\{C_{41}, C_{42}, C_{43}\right\}\right)=1$ \\
\hline
\end{tabular}

Source: Liou et al. (2012).

Table 6. Gap ratio values of potential suppliers by Fuzzy Integral

\begin{tabular}{|c|c|c|c|c|c|c|}
\hline \multirow[t]{2}{*}{ Criteria } & \multirow{2}{*}{$\begin{array}{c}\text { Weights } \\
\text { Local }\end{array}$} & \multicolumn{5}{|c|}{ Alternatives } \\
\hline & & $A_{1}$ & $A_{2}$ & $A_{3}$ & $A_{4}$ & $A_{5}$ \\
\hline Compatibility $\left(D_{1}\right)$ & 0.306 & 0.240 & 0.179 & 0.197 & 0.182 & 0.263 \\
\hline Relationship $\left(C_{11}\right)$ & 0.367 & 0.264 & 0.208 & 0.199 & 0.198 & 0.268 \\
\hline Flexibility $\left(C_{12}\right)$ & 0.310 & 0.214 & 0.211 & 0.198 & 0.176 & 0.264 \\
\hline Information sharing $\left(C_{13}\right)$ & 0.324 & 0.242 & 0.175 & 0.194 & 0.173 & 0.258 \\
\hline Quality $\left(D_{2}\right)$ & 0.231 & 0.286 & 0.224 & 0.227 & 0.227 & 0.214 \\
\hline Knowledge skills $\left(C_{21}\right)$ & 0.281 & 0.280 & 0.221 & 0.275 & 0.224 & 0.214 \\
\hline Customer satisfaction $\left(C_{22}\right)$ & 0.379 & 0.286 & 0.255 & 0.227 & 0.265 & 0.203 \\
\hline On time rate $\left(C_{23}\right)$ & 0.340 & 0.302 & 0.213 & 0.213 & 0.214 & 0.246 \\
\hline $\operatorname{Cost}\left(D_{3}\right)$ & 0.204 & 0.242 & 0.300 & 0.327 & 0.339 & 0.268 \\
\hline Cost saving $\left(C_{31}\right)$ & 0.506 & 0.246 & 0.333 & 0.313 & 0.324 & 0.267 \\
\hline Flexibility in billing $\left(C_{32}\right)$ & 0.494 & 0.239 & 0.278 & 0.348 & 0.362 & 0.269 \\
\hline Risk $\left(D_{4}\right)$ & 0.259 & 0.252 & 0.245 & 0.227 & 0.249 & 0.277 \\
\hline Labor unions $\left(C_{41}\right)$ & 0.327 & 0.257 & 0.292 & 0.214 & 0.219 & 0.275 \\
\hline Loss of management control $\left(C_{42}\right)$ & 0.351 & 0.255 & 0.208 & 0.218 & 0.248 & 0.288 \\
\hline Information security $\left(C_{43}\right)$ & 0.322 & 0.242 & 0.235 & 0.249 & 0.278 & 0.268 \\
\hline $\begin{array}{l}\text { Total gap } \\
\text { (rank) }\end{array}$ & - & $\begin{array}{c}0.359 \\
(3)\end{array}$ & $\begin{array}{c}0.350 \\
(2)\end{array}$ & $\begin{array}{c}0.345 \\
(1)\end{array}$ & $\begin{array}{c}0.361 \\
(4)\end{array}$ & $\begin{array}{c}0.376 \\
(5)\end{array}$ \\
\hline
\end{tabular}

Note: For example Alternative $\left.\left.A_{1}, D_{1}:(0.264-0.242) \times 0.330\right)+(0.242-0.214) \times 0.656\right)+(0.214 \times 1)=0.240$, total ratio gap: $(0.286-0.252) \times 0.314)+(0.252-0.242) \times 0.600)+(0.242-0.240) \times 0.778)+(0.240 \times 1)=0.359$ (non-additive). Source: Liou et al. (2012). 
In the case study, the proposed fuzzy integral-based model addresses this problem, and the results reveal a different priority: $A_{3} \succ A_{2} \succ A_{1} \succ A_{4} \succ A_{5}$ (Table 6). Obviously, $A_{3}$ is the best service provider considering both the criterion weights and performance interdependence. This non-additive model should be more reasonable than previous additive models because if network relationships exist between criteria, the performances should have the same effect (the contents summarized from Tzengs' research group (Liou et al. 2012)).

\section{Conclusions}

This study proposed some important new concepts and limit limitations/defects of traditional MADM. Additionally, this study presented empirical cases to demonstrate that the HDMADM method could overcome the defects of the conventional MADM method. First, the traditional model assumes that the criteria are independent and hierarchical in structure; however, realworld problems frequently involve interdependent criteria. This study presented a HDMADM method that applies the characteristics of influential weights ANP and combines them with DEMATEL (call DANP, DEMATEL-based ANP) to solve interdependence and feedback problems of criteria. Second, the VIKOR method set the best $f_{j}^{*}$ values as the aspiration level and the worst $f_{j}^{-}$values as the tolerable level for all criterion functions, $j=1,2, \ldots, n$ to avoid "Choosing the best among a range of inferior choices/options/alternatives" (i.e. this study avoids picking the best from a barrel of rotten apples). Third, the HDMADM method shifts the concept from the "ranking" or "selection" of the most preferable alternatives to the "improvement" of their performances or competitiveness to achieve the aspiration level based on influential network relation map (INRM) using the DEMATEL technique. Finally, this study describes an empirical case involving supplier evaluation and improvement of Taiwanese company based on a novel fuzzy integral-based hybrid MADM model that addresses the dependence/relationships among the various criteria and non-additive gap-weighted analysis.

\section{References}

Campanella, G.; Ribeiro, R. A. 2011. A framework for dynamic multiple-criteria decision making, Decision Support Systems 52(1): 52-60. http://dx.doi.org/10.1016/j.dss.2011.05.003

Carlsson, C.; Fullr, R. 1996. Fuzzy multiple criteria decision making: recent developments, Fuzzy Sets and Systems 78(2): 139-153. http://dx.doi.org/10.1016/0165-0114(95)00165-4

Chang, P. L.; Hsu, C. W.; Lin, C. Y. 2012. Assessment of hydrogen fuel cell applications using fuzzy multiple-criteria decision making method, Applied Energy 100: 93-99.

http://dx.doi.org/10.1016/j.apenergy.2012.03.051

Chen, T. Y.; Chang, C. C.; Tzeng, G. H. 2001a. Applying fuzzy measures to establish priority-setting procedures for the pavement management system, PanPacific Management Review 4(1): 23-33.

Chen, T. Y.; Chang, H. L.; Tzeng, G. H. 2001b. Using a weight-assessing model to identify route choice criteria and information effects, Transportation Research Part A 35(3): 197-224. http://dx.doi.org/10.1016/S0965-8564(99)00055-5

Chen, T. Y.; Wang, J. C.; Tzeng, G. H. 2000. Identification of general fuzzy measures by genetic algorithms based on partial information, IEEE Transactions on Systems, Man, and Cybernetics Part B: Cybernetics 30B(4): 517-528. http://dx.doi.org/10.1109/3477.865169 
Chen, Y. C.; Lien, H. P.; Tzeng, G. H. 2010. Measures and evaluation for environment watershed plans using a novel hybrid MCDM model, Expert Systems with Applications 37(2): 926-938. http://dx.doi.org/10.1016/j.eswa.2009.04.068

Chen, Y. K.; Liao, H. C. 2004. Multi-criteria design of an X control chart, Computers and Industrial Engineering 46(4): 877-891. http://dx.doi.org/10.1016/j.cie.2004.05.020

Chiou, H. K.; Tzeng, G. H. 2002. Fuzzy multi-criteria decision-making approach to analysis and evaluation of green engineering for industry, Environmental Management 30(6): 816-830. http://dx.doi.org/10.1007/s00267-002-2673-z

Chiou, H. K.; Tzeng, G. H. 2003. An extended approach of multicriteria optimization for MODM problems, in Tanino, T.; Tanaka, T.; Inuiguchi, M. (Eds.). Multi-Objective Programming and Goal-Programming: Theory and Applications. Springer-Verlag, 111-116.

Chiou, H. K.; Tzeng, G. H.; Cheng, D. C. 2005. Evaluating sustainable fishing development strategies using fuzzy MCDM approach, Omega Journal (The International Journal of Management Science) 33(3): 223-234. http://dx.doi.org/10.1016/j.omega.2004.04.011

Chiu, W. Y.; Tzeng, G. H.; Li, H. L. 2013. A new hybrid MCDM model combining DANP with VIKOR to improve e-store business, Knowledge-Based Systems 37(1): 48-61. http://dx.doi.org/10.1016/j.knosys.2012.06.017

Chou, W. C.; Cheng, Y. P. 2012. A hybrid fuzzy MCDM approach for evaluating website quality of professional accounting firms, Expert Systems with Applications 39(3): 2783-2793. http://dx.doi.org/10.1016/j.eswa.2011.08.138

Chu, M. T.; Shyu, J. Z.; Tzeng, G. H. 2007. Using non-additive fuzzy integral to assess performances of organization transformation via communities of practice, IEEE Transactions on Engineering Management 54(2): 327-339. http://dx.doi.org/10.1109/TEM.2007.893987

Deng, Y.; Chan, T. S. F. 2011. A new fuzzy dempster MCDM method and its application in supplier selection, Expert Systems with Applications 38(8): 9854-9861. http://dx.doi.org/10.1016/j.eswa.2011.02.017

Ho, W. R. J.; Tsai, C. L.; Tzeng, G. H.; Fang, S. K. 2011. Combined DEMATEL technique with a novel MCDM model for exploring portfolio selection based on CAPM, Expert Systems with Applications 38(1): 16-25. http://dx.doi.org/10.1016/j.eswa.2010.05.058

Hung, C. Y.; Chiang, Y. H. 2008. A fuzzy MCDM application for evaluation of factoring from the purchaser's perspective, Journal of American Academy of Business, Cambridge 13(2): 196-204.

Hwang, C. L.; Yoon, K. 1981. Multiple attribute decision making: methods and applications. Springer-Verlag, NY. http://dx.doi.org/10.1007/978-3-642-48318-9

Ishii, K.; Sugeno, M. 1985. A model of human evaluation process using fuzzy measure, International Journal of Man-Machine Studies 22(1): 19-38. http://dx.doi.org/10.1016/S0020-7373(85)80075-4

Jankowski, P. 1995. Integrating geographical information systems and multiple criteria decision making methods, International Journal of Geographical Information Systems 9(3): 251-273.

http://dx.doi.org/10.1080/02693799508902036

Kuo, M. S. 2011. A novel interval-valued fuzzy MCDM method for improving airlines' service quality in Chinese cross-strait airlines, Transportation Research Part E: Logistics and Transportation Review 47(6): 1177-1193. http://dx.doi.org/10.1016/j.tre.2011.05.007

Larbani, M.; Huang, C. Y.; Tzeng, G. H. 2011. A novel method for fuzzy measure identification, International Journal of Fuzzy Systems 13(1): 24-34.

Lee, W. S.; Tzeng, G. H.; Cheng, C. M. 2009. Using novel MCDM methods based on Fama-French threefactor model for probing the stock selection, APIEMS Dec. 14-16: 1460-1474.

Lin, C. L.; Tzeng, G. H. 2009. A value-created system of science (technology) park by using DEMATEL, Expert Systems with Applications 36(6): 9683-9697. http://dx.doi.org/10.1016/j.eswa.2008.11.040 
Liou, J. H. J.; Tzeng, G. H. 2012. Comments on "Multiple criteria decision making (MCDM) methods in economics: an overview", Technological and Economic Development of Economy 18(4): 672-695. http://dx.doi.org/10.3846/20294913.2012.753489

Liou, J. H. J.; Chuang, Y. C.; Tzeng, G. H. 2012. Combine ANP and Fuzzy integral approaches for supplier evaluation and selection, in EURO, $25^{\text {th }}$ European Conference on Operational Research, July. 08-11.41 p.

Liou, J. H. J.; Tzeng, G. H. 2007. A non-additive model for evaluating airline service quality, Journal of Air Transport Management 13(3): 131-138. http://dx.doi.org/10.1016/j.jairtraman.2006.12.002

Liu, H. T. 2011. Product design and selection using fuzzy QFD and fuzzy MCDM approaches, Applied Mathematical Modelling 35(1): 482-496. http://dx.doi.org/10.1016/j.apm.2010.07.014

Loban, S. R. 1997. A framework for computer-assisted travel counseling, Annals of Tourism Research 24(4): 813-834. http://dx.doi.org/10.1016/S0160-7383(97)00027-3

Luce, R. D.; Raiffa, H. 1957. Games and decisions: introduction and critical survey. New York: Wiley.

Mollaghasemi, M.; Pet-Edwards, J. 1997. Making multiple-objective decisions. Los Alamitos: IEEE Computer Society Press.

Opricovic, S. 1998. Multicriteria optimization of civil engineering systems. Faculty of Civil Engineering, Belgrade.

Opricovic, S.; Tzeng, G. H. 2002. Multicriteria planning of post-earthquake sustainable reconstruction, Computer-Aided Civil and Infrastructure Engineering 17(3): 211-220. http://dx.doi.org/10.1111/1467-8667.00269

Opricovic, S.; Tzeng, G. H. 2003. Fuzzy multicriteria model for post-earthquake land-use planning, Natural Hazards Review 4(2): 59-64. http://dx.doi.org/10.1061/(ASCE)1527-6988(2003)4:2(59)

Opricovic, S.; Tzeng, G. H. 2004. Compromise solution by MCDM methods: a comparative analysis of VIKOR and TOPSIS, European Journal of Operational Research 156(2): 445-455. http://dx.doi.org/10.1016/S0377-2217(03)00020-1

Opricovic, S.; Tzeng, G. H. 2007. Extended VIKOR method in comparison with outranking methods, European Journal of Operational Research 178(2): 514-529. http://dx.doi.org/10.1016/j.ejor.2006.01.020

Ou Yang, Y. P.; Shieh, H. M.; Leu, J. D.; Tzeng, G. H. 2008. A novel hybrid MCDM model combined with DEMATEL and ANP with applications, International Journal of Operations Research 5(3): 160-168.

Saaty, T. L. 1996. Decision making with dependence and feedback: the analytic network process. Pittsburgh, PA: RWS Publications.

Streimikiene, D.; Balezentis, T.; Krisciukaitienè, I.; Balezentis, A. 2012. Prioritizing sustainable electricity production technologies: MCDM approach, Renewable and Sustainable Energy Reviews 16(5): 3302-3311. http://dx.doi.org/10.1016/j.rser.2012.02.067

Sugeno, M. 1974. Theory of fuzzy integrals and its applications: PhD Thesis, Tokyo Institute of Technology, Japan.

Sugeno, M.; Narukawa, Y.; Murofushi, T. 1998. Choquet integral and fuzzy measures on locally compact space, Fuzzy Sets and Systems 99(2): 205-211. http://dx.doi.org/10.1016/S0165-0114(97)00028-6

Tsaur, S. H.; Tzeng, G. H.; Wang, G. C. 1997. The application of AHP and fuzzy MCDM on the evaluation study of tourist risk, Annals of Tourism Research 24(4): 796-812. http://dx.doi.org/10.1016/S0160-7383(97)00059-5

Tseng, M. L. 2011. Using hybrid MCDM to evaluate the service quality expectation in linguistic preference, Applied Soft Computing 11(8): 4551-4562. http://dx.doi.org/10.1016/j.asoc.2011.08.011

Tzeng, G. H.; Chiang, C. H.; Li, C. W. 2007. Evaluating intertwined effects in e-learning programs: a novel hybrid MCDM model based on factor analysis and DEMATEL, Expert Systems with Applications 32(4): 1028-1044. http://dx.doi.org/10.1016/j.eswa.2006.02.004 
Tzeng, G. H.; Huang, J. J. 2011. Multiple attribute decision making: methods and applications. CRC Press, Taylor \& Francis Group, a Chapman \& Hall Book.

Tzeng, G. H.; Lin, C. W.; Opricovic, S. 2005. Multi-criteria analysis of alternative-fuel buses for public transportation, Energy Policy 33(11): 1373-1383. http://dx.doi.org/10.1016/j.enpol.2003.12.014

Tzeng, G. H.; Teng, M. H.; Chen, J. J.; Opricovic, S. 2002b. Multicriteria selection for a restaurant location in Taipei, International Journal of Hospitality Management 21(2): 171-187. http://dx.doi.org/10.1016/S0278-4319(02)00005-1

Tzeng, G. H.; Tsaur, S. H.; Laiw, Y. D.; Opricovic, S. 2002a. Multicriteria analysis of environmental quality in Taipei: public preferences and improvement strategies, Journal of Environmental Management 65(2): 109-120. http://dx.doi.org/10.1006/jema.2001.0527

von Neumann, J.; Morgenstern, O. 1944. Theory of games and economic behavior. Princeton, NJ: Princeton University Press.

Wallenius, J.; Dyer, J. S.; Fishburn, P. C.; Steuer, R. E.; Zionts, S.; Deb, K. 2008. Multiple criteria decision making, multiattribute utility theory: recent accomplishments and what lies ahead, Management Science 54(7): 1336-1349. http://dx.doi.org/10.1287/mnsc.1070.0838

Wang, T. C.; Lee, H. D. 2009. Developing a fuzzy TOPSIS approach based on subjective weights and objective weights, Expert Systems with Applications 36(5): 8980-8985. http://dx.doi.org/10.1016/j.eswa.2008.11.035

Wu, H. Y.; Chen, J. K.; Chen, I. S.; Zhuo, H. H. 2012. Ranking universities based on performance evaluation by a hybrid MCDM model, Measurement 45(5): 856-880. http://dx.doi.org/10.1016/j.measurement.2012.02.009

Yu, P. L. 1973. A class of solutions for group decision problems, Management Science 19(8): 936-946. http://dx.doi.org/10.1287/mnsc.19.8.936 


\section{Appendix A. DEMATEL technique}

The DEMATEL technique is used to construct the interactions/interrelationship between criteria to build an influential relation map. The method is divided into three steps:

Step 1: Find the average influence matrix $\boldsymbol{A}$

The first step is to calculate initial matrix, using pair of degree of interaction/interrelationship to obtain directly influence matrix $\boldsymbol{A}=\left[a_{i j}\right]_{n \times n}$, where $a_{i j}$ represents the degree of effect on $i$ factor effects $j$ factor (Lin, Tzeng 2009; Chen et al. 2010).

$$
\boldsymbol{A}=\left[a_{i j}\right]_{n \times n}=\left[\frac{1}{H} \sum_{h=1}^{H} a_{i j}^{h}\right]_{n \times n},
$$

where $h$ is the $h^{\text {th }}$ expert and $h=1,2, \ldots, H$.

Step 2: Calculate the normalized influence matrix $\boldsymbol{X}$

When the elements of $i$ have a direct effect on the elements of $j$, then $a_{i j} \neq 0$, otherwise $a_{i j}=0$. The second step is to normalize the matrix. It can be obtained from Eqs. (2) and (3). Its diagonal is 0 , and maximum sum of row or column is 1 , but not all.

$$
X=s A \text {, }
$$

$$
\text { where } s=\min _{i, j}\left\{\frac{1}{\max \sum_{j=1}^{n} a_{i j}}, \frac{1}{\max \sum_{i=1}^{n} a_{i j}}\right\} i, j=1,2, \ldots, n \text {. }
$$

Step 3: Compute the total influence matrix $T$

The total-influence matrix $\boldsymbol{T}$ can be obtained through Eq. (4), in which $\boldsymbol{I}$ denotes the identity matrix.

$$
\boldsymbol{T}=\boldsymbol{X}+\boldsymbol{X}^{2}+\ldots+\boldsymbol{X}^{g}=\boldsymbol{X}(\boldsymbol{I}-\boldsymbol{X})^{-1}, \text { when } \lim _{g \rightarrow \infty} \boldsymbol{X}^{g}=[0]_{n \times n} .
$$

Explanation:

$$
\begin{aligned}
& \boldsymbol{T}=\boldsymbol{X}+\boldsymbol{X}^{2}+\cdots+\boldsymbol{X}^{g}= \\
& \boldsymbol{X}\left(\boldsymbol{I}+\boldsymbol{X}+\boldsymbol{X}^{2}+\cdots+\boldsymbol{X}^{g-1}\right)(\boldsymbol{I}-\boldsymbol{X})(\boldsymbol{I}-\boldsymbol{X})^{-1}= \\
& \boldsymbol{X}\left(\boldsymbol{I}-\boldsymbol{X}^{g}\right)(\boldsymbol{I}-\boldsymbol{X})^{-1}, \text { then } \\
& \boldsymbol{T}=\boldsymbol{X}(\boldsymbol{I}-\boldsymbol{X})^{-1}, \text { when } \lim _{g \rightarrow \infty} \boldsymbol{X}^{g}=[0]_{n \times n},
\end{aligned}
$$

where $\boldsymbol{X}=\left[x_{c}^{i j}\right]_{n \times n}, 0 \leq x_{c}^{i j}<1,0<\sum_{j=1}^{n} x_{c}^{i j} \leq 1$ and $0<\sum_{i=1}^{n} x_{c}^{i j} \leq 1$, and at least one row or column of the summation, but not all, equals one; then, $\lim _{\ell \rightarrow \infty} \boldsymbol{X}^{\ell}=[0]_{n \times n}$ can be guaranteed. 
To sum of each row and column of the total influence matrix $\boldsymbol{T}=\left[t_{i j}\right]_{n \times n}$, in these results the sum of all rows (vector $\left.\boldsymbol{r}=\left[\sum_{j=1}^{n} t_{i j}\right]_{n \times 1}=\left[r_{i}\right]_{n \times 1}=\left(r_{1}, \ldots, r_{i}, \ldots, r_{n}\right)^{\prime}\right)$ and the sum of all columns (vector $\boldsymbol{d}=\left[\sum_{i=1}^{n} t_{i j}\right]_{n \times 1}=\left[d_{j}\right]_{n \times 1}=\left(d_{1}, \ldots, d_{j}, \ldots, d_{n}\right)$ can be obtained. If $r_{i}$ represents the sum of all rows of the total-influence matrix $T$, meaning directly or/and indirectly affects to other criteria; $d_{j}$ represents the sum of all columns of the total-influence matrix $T$, meaning is affected by other criteria. $r_{i}$ represents the factor which will affect other factors, $d_{j}$ represents the factor that is affected by other factors. According to the definition, when $i=j$, then $r_{i}+d_{j}$ presents the degree of relationship between the factors, meaning "prominence"; $r_{i}-d_{j}$ presents the degree of effect and effected for the factors, meaning "relation" (Tzeng et al. 2007) in dynamic influence.

\section{Appendix B. To find the weights by DANP model}

DANP can be divided into following steps:

Step 1: Develop the structure of the question

The questions are clearly described then break them down to level structure.

Step 2: Develop Unweighted Supermatrix

Firstly, each level with total degree of effect that obtains from the total-influence matrix $\boldsymbol{T}$ of DEMATEL as shown in Eq. (5).

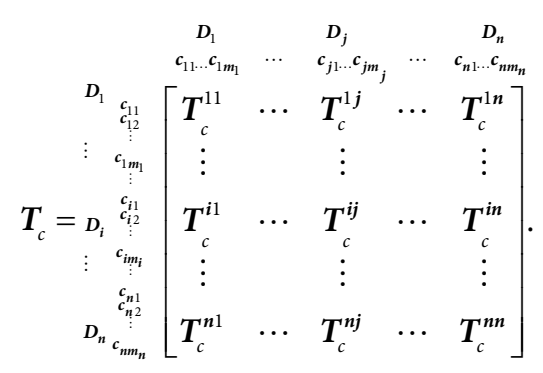

Normalize $\boldsymbol{T}_{c}$ with total-influence will be obtained $\boldsymbol{T}_{c}^{\alpha}$ that shows in Eq. (6).

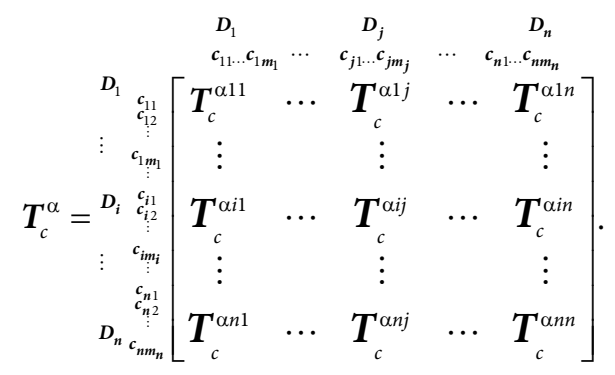


Normalize $\boldsymbol{T}_{c}^{\alpha 11}$ will be obtained by Eqs (7) and (8), according to the same fashion will be obtained $T_{c}^{\alpha n n}$.

$$
\begin{aligned}
& d_{i}^{11}=\sum_{j=1}^{m_{1}} t_{C i j}^{11}, i=1,2, \ldots, m_{1}
\end{aligned}
$$

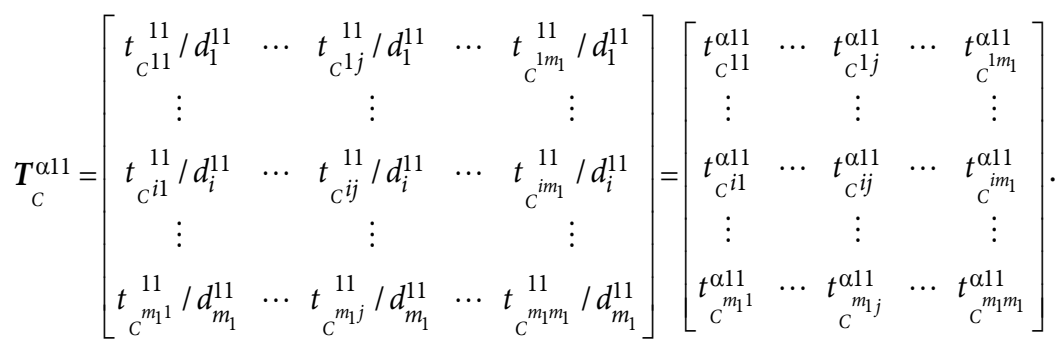

And then, total-influence matrix is normalized into Supermatrix according to the group in relying relationship to obtain Unweighted Supermatrix as show in Eq. (9).

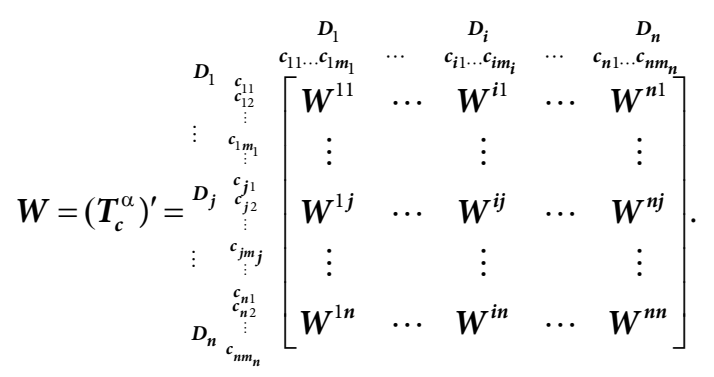

In addition, we will be obtained matrix $W^{11}$ and $W^{12}$ by Eq. (10). If blank or 0 shown in the matrix means the group or criteria is independent, according to the same fashion will be obtained matrix $\boldsymbol{W}^{n n}$.

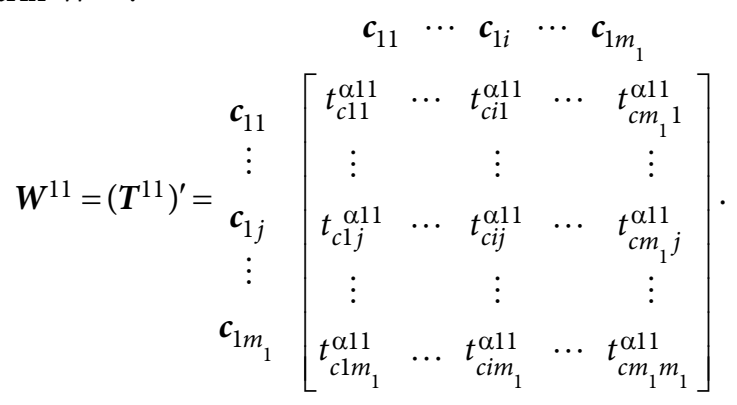

\section{Step 3: Obtain Weight Supermatrix}

Let each dimension of total-influence matrix $\boldsymbol{T}_{D}$ as (11) be normalized with total degree of influence to obtain $\boldsymbol{T}_{D}^{\alpha}$, the result as Eq. (12).

$$
d_{i}=\sum_{j=1}^{n} t_{D}^{i j}, i=1,2, \ldots, n
$$




$$
\begin{aligned}
& \boldsymbol{T}_{D}=\left[\begin{array}{ccccc}
t^{11} & \cdots & t^{1 j} & \cdots & t^{1 n} \\
D & & D & & D \\
\vdots & & \vdots & & \vdots \\
t^{i 1} & \cdots & t^{i j} & \cdots & t^{i n} \\
D & & D & & D \\
\vdots & & \vdots & & \vdots \\
t^{n 1} & \cdots & t^{n j} & \cdots & t^{n n} \\
D & & D & & D
\end{array}\right]
\end{aligned}
$$

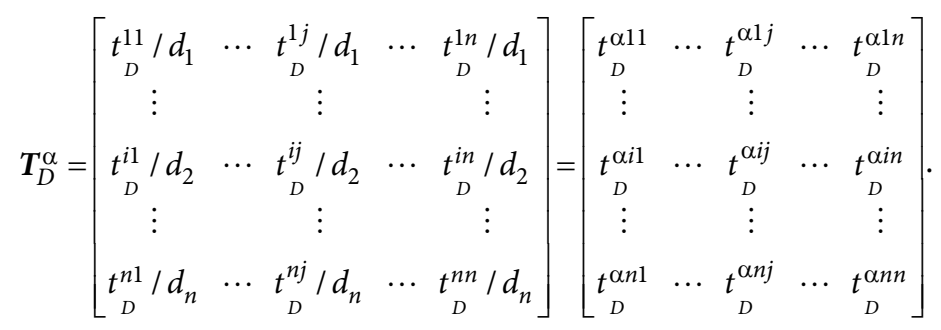

Then, drive the normalized $\boldsymbol{T}_{D}^{\alpha}$ into Unweight Supermatrix $\boldsymbol{W}$ to obtain Weight Supermatrix $W^{\alpha}$, the result as shown in Eq. (13):

$$
\boldsymbol{W}^{\alpha}=\boldsymbol{T}_{D}^{\alpha} \boldsymbol{W}=\left[\begin{array}{ccccc}
t_{D}^{\alpha 11} \times \boldsymbol{W}^{11} & \cdots & t_{D}^{\alpha i 1} \times \boldsymbol{W}^{i 1} & \cdots & t_{D}^{\alpha n 1} \times \boldsymbol{W}^{n 1} \\
\vdots & & \vdots & & \vdots \\
t_{D}^{\alpha 1 j} \times \boldsymbol{W}^{1 j} & \cdots & t_{D}^{\alpha i j} \times \boldsymbol{W}^{i j} & \cdots & t_{D}^{\alpha n j} \times \boldsymbol{W}^{n j} \\
\vdots & & \vdots & & \vdots \\
t_{D}^{\alpha 1 n} \times \boldsymbol{W}^{1 n} & \cdots & t_{D}^{\alpha i n} \times \boldsymbol{W}^{i n} & \cdots & t_{D}^{\alpha n n} \times \boldsymbol{W}^{n n}
\end{array}\right] .
$$

Step 4: Obtain limit supermatrix

According to the weighted super-matrix $W^{\alpha}$, it multiplies by itself multiple times to obtain limit supermatrix based on basic concept of Markov Chain. Then, the DANP influential weights of each criterion can be obtained by $\lim _{z \rightarrow \infty}\left(\boldsymbol{W}^{\alpha}\right)^{z}$, where $z$ represents any number for power.

\section{Appendix C. VIKOR method}

VIKOR method can be divided into follow steps:

Step 1: Check the best value $f_{j}^{*}$ and the worse value $f_{j}^{-}$

There $f_{j}^{*}$ represents the positive-ideal point, that means the expert gives the scores of the best value (aspired levels) in each criterion and $f_{j}^{-}$represents the negative-ideal point, that means the expert gives the scores of the worst values in each criterion. We use Eqs. (14) and (15) to obtain the results.

$$
\begin{aligned}
& f_{j}^{*}=\max _{k} f_{k j}, j=1,2, \ldots, n \text { (traditional approach), } \\
& \text { or setting the aspired levels, vector } f^{*}=\left(f_{1}^{*}, f_{2}^{*}, \cdots, f_{n}^{*}\right),
\end{aligned}
$$




$$
\begin{aligned}
& f_{j}^{-}=\min _{k} f_{k j}, j=1,2, \ldots, n \text { (traditional approach), } \\
& \text { or setting the worst values, vector } f^{-}=\left(f_{1}^{-}, f_{2}^{-}, \cdots, f_{n}^{-}\right) .
\end{aligned}
$$

We set the best $f_{j}^{*}$ values to be the aspiration level and the worst $f_{j}^{-}$values as the tolerable level for all criterion functions, $j=1,2, \ldots, n$. In this study, we modify the traditional approach (suppose the $j$ th function denotes benefits: $f_{j}^{*}=\max _{k} f_{k j}$ and $f_{j}^{-}=\min _{k} f_{k j}$ ) and shift the concept from the "ranking" or "selection" of the most preferable alternatives to the "improvement" of their performances to achieve the aspiration level for each dimension and criterion. Therefore, the $f_{j}^{*}$ and $f_{j}^{-}$values can be set by decision makers, so that $f_{j}^{*}$ is the aspiration level and $f_{j}^{-}$is the worst value. For example, in questionnaires we can use performance scores ranging from 0 to 10 (from very dissatisfied or very bad $\leftarrow 0,1,2, \ldots, 9,10 \rightarrow$ very satisfied or very good) expressed natural language, wherein the aspiration level can be set at 10 and the worst value at zero. In this study, we set $f_{j}^{\star}=10$ as the aspiration level and $f_{j}^{-}=0$ as the worst value, which differs from the traditional approach. This allows us to avoid "choosing the best among inferior options/alternatives (i.e. avoid picking the best apple from among a barrel of rotten apples)".

Step 2: Calculate the mean of group utility $S_{k}$ and maximal regret $Q_{k}$

There $S_{k}$ represents the ratios of distance to the positive-ideal, it means the synthesized gap for all criteria; $w_{j}$ represents the influential weights of the criteria from DANP; $r_{k j}$ represents the average gap-ratios (regret) of normalized distance to the aspired level point, and $Q_{k}$ represents the maximal gap-ratios (regret) of normalized distance to the aspired level in all criteria, it means the maximal gap in $j$ criteria for prior improvement. Those values can be computed respectively by Eqs. (16) and (17).

$$
\begin{gathered}
S_{k}=\sum_{j=1}^{n} w_{j} r_{k j}=\sum_{j=1}^{n} w_{j}\left(\left|f_{j}^{*}-f_{k j}\right|\right) /\left(\left|f_{j}^{*}-f_{j}^{-}\right|\right) ; \\
Q_{k}=\max _{j}\left\{r_{k j} \mid j=1,2, \ldots, n\right\} .
\end{gathered}
$$

Step 3: Obtain the comprehensive indicator $R_{k}$ and sorting results

The values can be computed respectively by Eq. (18).

$$
R=v\left(S_{k}-S^{*}\right) /\left(S^{-}-S^{*}\right)+(1-v)\left(Q_{k}-Q^{*}\right) /\left(Q^{-}-Q^{*}\right) .
$$

Those values derived from $S^{*}=\min _{k} S_{k}$ or setting $S^{*}=0$ (the aspired level), $S^{-}=\max _{k} S_{k}$ or setting $S^{-}=1$ (the worst situation); $Q^{*}=\min _{k} Q_{k}$ or setting $Q^{*}=0$ (the aspired level), and $Q^{-}=\max _{k} Q_{k}$ or setting $Q^{-}=1$ (the worst situation). Therefore, when $S^{*}=0$ and $S^{-}=1$, and $Q^{\star}{ }^{k}=0$ and $Q^{-}=1$, we can re-write the Eq. (43) as $R_{k}=v S_{k}+(1-v) Q_{k}$. Weight $v=1$ represents only to be consider the average gap (average regret) weight and weight $v=0$ represents only to be consider the max gap to be prior improvement. It can provide the decision-makers by experts. Generally $v=0.5$ (the majority of criteria), it could be adjusted depends on the situation. 


\section{Appendix $D$. The $\lambda$ fuzzy measure and fuzzy integral}

Let $g_{\lambda}$ denote a $\lambda$ fuzzy measure which is defined on a power set $P(x)$, for the finite set $X=\left\{x_{1}, x_{2}, \ldots, x_{n}\right\}$. The fuzzy measure has the following property (Tzeng, Huang 2011):

$$
\begin{gathered}
\forall A, B \in P(X), \quad A \cap B=\varnothing, \\
g_{\lambda}(A \cup B)=g_{\lambda}(A)+g_{\lambda}(B)+\lambda g_{\lambda}(A) g_{\lambda}(B) \text { for }-1<\lambda<\infty .
\end{gathered}
$$

The density of the fuzzy measure $g_{i}=g_{\lambda}\left(\left\{x_{i}\right\}\right)$ can be obtained from questionnaire responses (thus $\left.g_{\lambda}\left(\left\{x_{i}\right\}\right)=u\left(x_{i}^{*}, x_{i}^{0}\right)\right)$. Assume the existence of a single product, for which all criteria are perfect, and where the product equals 1 . Now assume that for this product only one criterion $x_{i}^{*}$ is completely perfect, while besides $x_{i}^{*}$ all other criteria $x_{i}^{0}$ are inferior. The question becomes the attractiveness of the product in this situation. The local weights $\left(w_{1}, w_{2}, \ldots, w_{n}\right)$ can be obtained using DANP. Next, the fuzzy measure weights are set to:

$$
\left(g_{\lambda}\left(\left\{x_{1}\right\}\right), g_{\lambda}\left(\left\{x_{2}\right\}\right), \ldots, g_{\lambda}\left(\left\{x_{n}\right\}\right)\right)=q\left(w_{1}, w_{2}, \ldots, w_{n}\right)=\left(w_{1} q, w_{2} q, \ldots, w_{n} q\right),
$$

where $q$ denotes the adjusted weight coefficient.

$$
\begin{aligned}
& g_{\lambda}\left(\left\{x_{1}, x_{2}, \ldots, x_{n}\right\}\right)=\sum_{i=1}^{n} g_{\lambda}\left(\left\{x_{i}\right\}\right)+\lambda \sum_{i=1, j>i}^{n} g_{\lambda}\left(\left\{x_{i}\right\}\right) g_{\lambda}\left(\left\{x_{j}\right\}\right)+\ldots \\
& \lambda^{n-1} g_{\lambda}\left(\left\{x_{1}\right\}\right) g_{\lambda}\left(\left\{x_{2}\right\}\right) \ldots g_{\lambda}\left(\left\{x_{n}\right\}\right), \text { where } g_{\lambda}(X)=g_{\lambda}\left(\left\{x_{1}, x_{2}, \ldots, x_{n}\right\}\right)=1 .
\end{aligned}
$$

Based on the above properties, one of the three following situations is sustained for a specific case involving attributes, $x_{1}$ and $x_{2}$.

a. If $1>0$, then $\boldsymbol{g}_{\lambda}(\boldsymbol{A} \cup \boldsymbol{B})>\boldsymbol{g}_{\lambda}(\boldsymbol{A})+\boldsymbol{g}_{\lambda}(\boldsymbol{B})$ which implies that $x_{1}$ and $x_{2}$ have a multiplicative effect in $\{A, B\}$;

b. If $1=0$, then $\boldsymbol{g}_{\lambda}(\boldsymbol{A} \cup \boldsymbol{B})=\boldsymbol{g}_{\lambda}(\boldsymbol{A})+\boldsymbol{g}_{\lambda}(\boldsymbol{B})$ which implies that $x_{1}$ and $x_{2}$ have an additive effect in $\{A, B\}$;

c. If $1<0$, then $\boldsymbol{g}_{\lambda}(\boldsymbol{A} \cup \boldsymbol{B})<\boldsymbol{g}_{\lambda}(\boldsymbol{A})+\boldsymbol{g}_{\lambda}(\boldsymbol{B})$ which means that $x_{1}$ and $x_{2}$ have a substitutive effect in $\{A, B\}$.

In this model, the performance values are replaced by the gaps which equal aspiration levels minus the evaluated values with respect to each criterion. Let $h$ denote a measurable set function (gap function) defined on the fuzzy measurable space, and supposing that $h\left(x_{1}\right) \geq h\left(x_{2}\right) \geq \ldots \geq h\left(x_{n}\right)$, then the fuzzy integral of fuzzy measure $g(\cdot)$ with respect to $h(\cdot)$ can be defined as follows (Ishii, Sugeno 1985), as shown in Fig. D1.

$$
\begin{gathered}
\int h \mathrm{~d} g=h\left(x_{n}\right) g\left(H_{\mathrm{n}}\right)+\left[h\left(x_{n-1}\right)-h\left(x_{n}\right)\right] g\left(H_{n-1}\right)+\ldots+\left[h\left(x_{1}\right)-h\left(x_{2}\right)\right] g\left(H_{1}\right)= \\
h\left(x_{n}\right)\left[g\left(H_{\mathrm{n}}\right)-g\left(H_{\mathrm{n}-1}\right)\right]+h\left(x_{n-1}\right)\left[g\left(H_{n-1}\right)-g\left(H_{\mathrm{n}-2}\right)\right]+\ldots+h\left(x_{1}\right) g\left(H_{1}\right),
\end{gathered}
$$

where $H_{1}=\left\{x_{1}\right\}, H_{2}=\left\{x_{1}, x_{2}\right\}, \ldots, H_{n}=\left\{x_{1}, x_{2}, \ldots, x_{n}\right\}=X$. 


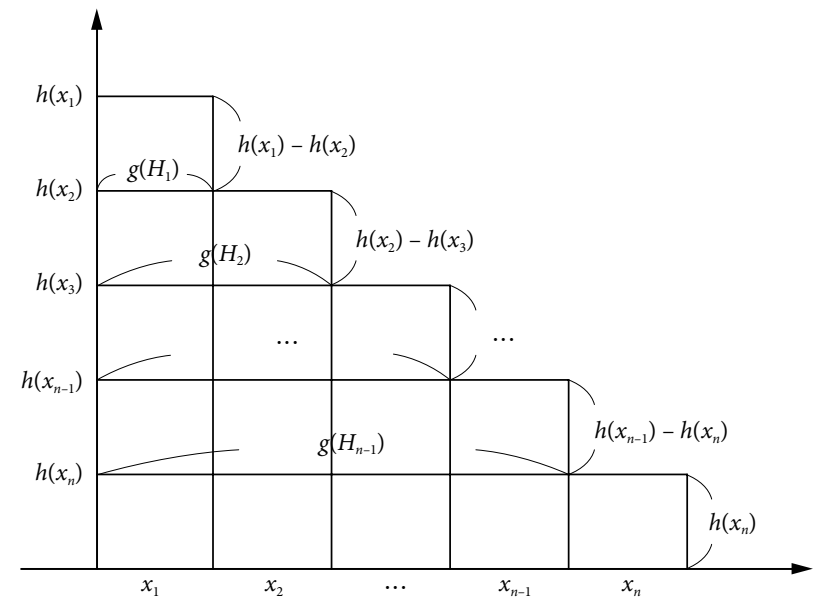

Fig. D1. Concept of fuzzy integral

The fuzzy integral defined in Eq. (22) is called the Choquet integral (Sugeno 1974; Ishii, Sugeno 1985; Sugeno et al. 1998; Chen et al. 2000, 2001a; Chiou, Tzeng 2002, 2003; Chiou et al. 2005; Liou, Tzeng 2007; Chu et al. 2007; Larbani et al. 2011). Using the fuzzy integral to formulate the original data can not only extract fewer and more representative factors to describe the system, but can also consider the interactions between attributes. This study used $\int h \mathrm{dg}=a_{i n}$ as the integrated weighted gaps of cluster $C_{n}$ at alternative $i$.

Kua-Hsin PENG received her PhD degree from the Department of Management Science of National Chiao Tung University, Taiwan in 2011. Currently, she is an Assistant Professor in the Department of Leisure and Recreation Management at Kainan University. She has published in numerous journals, including Tourism Management, Current Issues in Tourism, Journal of the Operational Research Society, Quality \& Quantity, Expert Systems with Applications, Journal of Grey System, etc. Her research interest is applying hybrid MCDM method to solve some problems in tourism and leisure management, accreditation performance, etc.

Gwo-Hshiung TZENG. In 1967, he received the Bachelor's degree in Business Management from the Tatung Institute of Technology (now Tatung University), Taiwan; in 1971, he received the Master's degree in Urban Planning from Chung Hsing University (Now Taipei University), Taiwan; and in 1977, he received the $\mathrm{PhD}$ degree course in management science from Osaka University, Osaka, Japan. He was an Associate Professor at Chiao Tung University, Taiwan (1977-1981), a Research Associate at Argonne National Laboratory (July 1981-January 1982), a Visiting Professor in the Department of Civil Engineering at the University of Maryland, College Park (August 1989-August 1990), a Visiting Professor in the Department of Engineering and Economic System, Energy Modeling Forum at Stanford University (August 1997-August 1998), a Professor at Chaio Tung University (1981-2003), and a Chair Professor at Chiao Tung University. His current research interests include statistics, multivariate analysis, network, routing and scheduling, multiple criteria decision making, fuzzy theory, hierarchical structure analysis for applying to technology management, energy, environment, transportation systems, transportation investment, logistics, location, urban planning, tourism, technology management, electronic commerce, global supply chain, etc. 